\title{
In-situ Effects of Eutrophication and Overfishing on Physiology and Bacterial Diversity of the Red Sea Coral Acropora hemprichii
}

\author{
Christian Jessen ${ }^{1}$, Javier Felipe Villa Lizcano ${ }^{2}$, Till Bayer $^{2}$, Cornelia Roder ${ }^{2}$, Manuel Aranda ${ }^{2}$, \\ Christian Wild ${ }^{1,3}$, Christian R. Voolstra ${ }^{2 *}$
}

1 Coral Reef Ecology Group (CORE), Leibniz Center for Tropical Marine Ecology (ZMT), Bremen, Germany, 2 Red Sea Research Center, KAUST, Thuwal, Saudi Arabia, 3 Faculty of Biology and Chemistry, University of Bremen, Bremen, Germany

\begin{abstract}
Coral reefs of the Central Red Sea display a high degree of endemism, and are increasingly threatened by anthropogenic effects due to intense local coastal development measures. Overfishing and eutrophication are among the most significant local pressures on these reefs, but there is no information available about their potential effects on the associated microbial community. Therefore, we compared holobiont physiology and 16S-based bacterial communities of tissue and mucus of the hard coral Acropora hemprichii after 1 and 16 weeks of in-situ inorganic nutrient enrichment (via fertilizer diffusion) and/or herbivore exclusion (via caging) in an offshore reef of the Central Red Sea. Simulated eutrophication and/or overfishing treatments did not affect coral physiology with respect to coral respiration rates, chlorophyll $a$ content, zooxanthellae abundance, or $\delta{ }^{15} \mathrm{~N}$ isotopic signatures. The bacterial community of $A$. hemprichii was rich and uneven, and diversity increased over time in all treatments. While distinct bacterial species were identified as a consequence of eutrophication, overfishing, or both, two bacterial species that could be classified to the genus Endozoicomonas were consistently abundant and constituted two thirds of bacteria in the coral. Several nitrogen-fixing and denitrifying bacteria were found in the coral specimens that were exposed to experimentally increased nutrients. However, no particular bacterial species was consistently associated with the coral under a given treatment and the single effects of manipulated eutrophication and overfishing could not predict the combined effect. Our data underlines the importance of conducting field studies in a holobiont framework, taking both, physiological and molecular measures into account.
\end{abstract}

Citation: Jessen C, Villa Lizcano JF, Bayer T, Roder C, Aranda M, et al. (2013) In-situ Effects of Eutrophication and Overfishing on Physiology and Bacterial Diversity of the Red Sea Coral Acropora hemprichii. PLoS ONE 8(4): e62091. doi:10.1371/journal.pone.0062091

Editor: Jack Anthony Gilbert, Argonne National Laboratory, United States of America

Received January 29, 2013; Accepted March 16, 2013; Published April 22, 2013

Copyright: (C) 2013 Jessen et al. This is an open-access article distributed under the terms of the Creative Commons Attribution License, which permits unrestricted use, distribution, and reproduction in any medium, provided the original author and source are credited.

Funding: No current external funding sources for this study.

Competing Interests: The authors have declared that no competing interests exist.

* E-mail: christian.voolstra@kaust.edu.sa

\section{Introduction}

Coral reefs are threatened by global (e.g. ocean acidification, ocean warming) and local (e.g. coral disease outbreaks, overfishing, eutrophication) anthropogenic stressors [1-4], whereby eutrophication and overfishing are among the two most important local factors affecting coral reef health [3]. On a macro-ecological scale, overfishing can reduce resilience of hard corals and the reefs that they are engineering [5] in numerous ways. Reduced herbivore stocks can lead to prolonged recovery times of corals after disturbances [6], increase crown-of-thorns starfish outbreaks [7], and release macroalgae from their top-down control [3]. Eutrophication, and more specifically nutrient enrichment, can have severe direct effects on scleractinian corals by hampering coral reproduction [8], reducing calcification [9,10], reducing the threshold of heat- and light stress mediated bleaching [11], advancing coral disease [12], and shifting microbial communities towards bacteria associated with diseased corals [13]. On the other hand, eutrophication affects scleractinian corals also indirectly by increasing turf and macroalgae [14-17], inhibit coral recruitment $[18,19]$, or directly outcompete corals via allelochemicals [20-22]. Furthermore, turf and macroalgae increase microbial activity and trigger changes in the microbial community associated with corals [23-26] by dissolved organic carbon (DOC) release that can accelerate microbial growth and create a positive feedback loop when corals die and free space for more algae $[27,28]$.

The basic functional unit of coral reefs is the coral holobiont [29] that consists of a complex symbiotic interaction between the coral animal, its intracellular photosynthetic algae, and a wide spectrum of extra- and intracellular bacteria, archaea, fungi, eukaryotes, and viruses [29-32]. In contrast to the long history of studying the coral-algal relationship, understanding the importance of the bacterial assemblage in corals has only been recently targeted. Initial studies showed that the microbial community of corals is diverse, complex, and uneven [31-33]. Furthermore, bacterial communities are species-specific $[31,33]$ and differ on a spatial [32,34], as well as a temporal scale [35]. Unlike most zooxanthellae, bacteria seem to be both stochastically and horizontally transmitted to the coral $[31,36]$. Their establishment, however, may depend on the variables associated with the environment and their genetic capability to colonize the coral niche under those specific conditions [37]. It becomes clear that corals are meta-organisms and their phenotypic responses are a result of the complex interplays between all member species. 
Hence, in order to comprehensively understand coral physiology, it is important to look at the interactions between host and symbionts and the prevailing environmental conditions.

A number of previous studies investigated the bacterial diversity in coral reef organisms via $16 \mathrm{~S}$ amplicon sequencing [32,34,35,38-40]. However, many of these studies analyzed a single point in time and space with limited indications towards the variance and stability of the microbial assemblage of the coral holobiont. Given the rate of decline of coral reef cover worldwide [41], it is becoming increasingly important to understand coral reef and coral holobiont functioning by combining physiological and molecular measures. Despite the fact that coral reefs in the Red Sea are of relative pristine condition, they are, too, challenged by the effects of coastal development and overfishing [42]. Hence, we set out to analyze coral physiology and associated changes of the microbial community of Acropora hemprichii in the Central Red Sea after 1 and 16 weeks of in situ artificial nutrient enrichment (using a fertilizer with 15\% nitrogen, 9\% phosphate, 12\% potassium oxide, and trace metals), in situ herbivore exclusion (using cages with a mesh size of $4 \mathrm{~cm}$ to exclude larger herbivores), and a combined treatment to simulate effects of eutrophication and overfishing. While the latter two processes generally refer to ecosystem scale effects, we were investigating effects on the scale of the holobiont in this study. To our knowledge, this is the first study from the Red Sea that evaluates top-down (i.e. herbivory) and bottom-up (i.e. nutrient availability) factors on coral holobiont functioning and provides first insights into the effects on coral physiology and associated bacterial community changes.

\section{Materials and Methods}

\section{Study Site and Organism}

The herbivore exclusion and nutrient enrichment experiments were carried out at Al-Fahal reef about $13 \mathrm{~km}$ off the Saudi Arabian coast in the Central Red Sea (N22 $18^{\prime} 19.98^{\prime \prime}$, E38 $57^{\circ} 46.08^{\prime \prime}$; Figure S1) over a period of 16 weeks from June to September 2011. Acropora hemprichii is a common reef building coral present in the Red Sea and the Western Indian Ocean [43], which inhabits upper reef slopes at this study site in the Red Sea. Al Fahal reef does not fall under any legislative protection or special designation as a marine/environmental protected area. No special permit is required for the inshore coastal, reef, and intertidal areas around Thuwal. The Saudi Coastguard Authority under the auspices of KAUST University issued sailing permits to the site that includes coral collection. Acropora hemprichii is listed as vulnerable on the ICUN Red List (http://www.iucnredlist.org/ details/132981/0).

\section{Experimental Design and Sampling}

The experimental setup included nine polyvinyl chloride (PVG) frames equipped with temperature loggers and stainless steel screws for coral finger attachment. Frames were deployed at 5$6 \mathrm{~m}$ water depth along a $40 \mathrm{~m}$ transect on a slightly sloped reef wall. Treatments were arranged in alternating order and separated from each other approximately by $2-5 \mathrm{~m}$. Treatments were: (1) caging (CA), with a cage mesh size of $4 \mathrm{~cm}$ to simulate overfishing of larger herbivores; (2) fertilizer (FE), perforated PVC tubes filled with Osmocote fertilizer standard 15+9+12 (Scotts, Marysville, $\mathrm{OH}$ ) embedded in 3\% agarose to simulate nutrient enrichment; (3) a combination of caging \& fertilizer (CF) (Figure S2). The fertilizer is composed of $15 \%$ nitrogen (in form of $7 \%$ nitrate and $8 \%$ ammonium), 9\% phosphate (phosphorus pentoxide), and $12 \%$ potassium oxide. Furthermore, it contains magnesium oxide $(2.5 \%)$, iron $(0.45 \%)$, manganese $(0.06 \%)$, copper $(0.056 \%)$, zinc
$(0.020 \%)$, boron $(0.020 \%)$, and molybdenum $(0.025 \%)$. Fertilizer was deployed once without replenishments, but regular monitoring of inorganic nutrient concentrations assured continuous enrichment levels (Figure 1). Experimental treatments were conducted in triplicates, i.e. three A. hemprichii colonies $(\mathrm{A}, \mathrm{B}, \mathrm{C})$ were collected from the same water depth in the area where the experiment was conducted. A total of nine frames were deployed (3 frames CA, 3 frames FE, 3 frames CF) each holding four coral fingers (for collection after 1 and 16 weeks) from each of the three mother colonies (A, B, C) yielding a total of 18 samples for physiological as well as for microbial analyses (3 treatments $\times 3$ coral colonies $\times 2$ time points). Experimental treatments started after attachment of coral fingers to the PVC frames via cable ties on stainless steel screws. After one and sixteen weeks, respectively, coral fingers were collected in sterile plastic bags and brought to the surface, where half of them were rinsed with filtered seawater (FSW) and subsequently shock-frozen in liquid nitrogen for microbial analyses and stored at $-80^{\circ} \mathrm{C}$ until further processing. The other half of the coral fragments was used for incubations (see coral physiology section below). Water samples for microbial and nutrient analyses were collected with large ziplock bags directly above each frame prior to coral fragment collection during both sampling time points. These samples were transported on ice and $500 \mathrm{~mL}$ were subsequently filtered on $0.22 \mu \mathrm{m}$ Millipore Durapore membrane filters for microbial analysis. Filters were stored at $-80^{\circ} \mathrm{C}$. Additionally, $50 \mathrm{~mL}$ seawater were filtered using $0.7 \mu \mathrm{m}$ fiberglass filters (Whatman-GF/F) and stored at $-20^{\circ} \mathrm{C}$ until inorganic nutrient analysis was carried out. The inorganic nutrients were photometrically analyzed by segmented debubbled continuous flow analysis (FlowSys - Alliance Instruments) according to [44] and for Ammonium according to [45]. Quality control was performed with a seawater certified reference material for nutrients (MOOS2 from NRG-CNRG).

\section{Coral Physiology}

Incubation measurements were performed as follows: coral fingers were transferred to $1 \mathrm{~L}$ incubation glass jars in three opaque polyethylene $(\mathrm{PE})$-boxes filled with reef water $(\sim 70 \mathrm{~L})$ to keep samples at constant ambient temperatures during incubations. One jar per PE-box, filled only with reef water, served as a control. All PE-boxes were placed in the shade to avoid warming of the water. Dark incubation started after acclimatizing the samples for 1-2 hours in the dark PE-boxes. Initial $\mathrm{O}_{2}$ concentrations were measured with an $\mathrm{O}_{2}$ probe (HQ40d, Hach, Loveland, CO) inside each box after evenly distributing the water, with open incubation jars. The jars were then sealed and incubated over a period of 90-100 min before $\mathrm{O}_{2}$ concentrations in each jar were measured as described above. During incubations the boxes were carefully moved every 5 minutes to cause stirring of water inside the jars. Onset HOBO temperature loggers (Onset Computer Corporation, Pocasset, MA) in each box assured that water temperature during incubation remained constant (temperature differences between incubation jars and in-situ temperatures measured at PVC frames ranged between 0.5 and $1.6^{\circ} \mathrm{C}$ ). All samples were subsequently stored on ice until further processing. Net $\mathrm{O}_{2}$ consumption was calculated subtracting end concentrations from the start concentrations. Normalization of data to $\mu \mathrm{g}$ $\mathrm{O}_{2} \mathrm{~cm}^{-2} \mathrm{~h}^{-1}$ was carried out by measuring the coral finger surface area using a cylinder as approximation according to the "simple geometry" model described by Naumann et al. [46] and by taking into account the exact incubation times. To investigate zooxanthellae abundance, chlorophyll $a$ concentration, and $\delta^{15} \mathrm{~N}$ isotopic signatures, tissue of each coral finger was washed with filtered sea water (FSW) before tissue was removed from the 

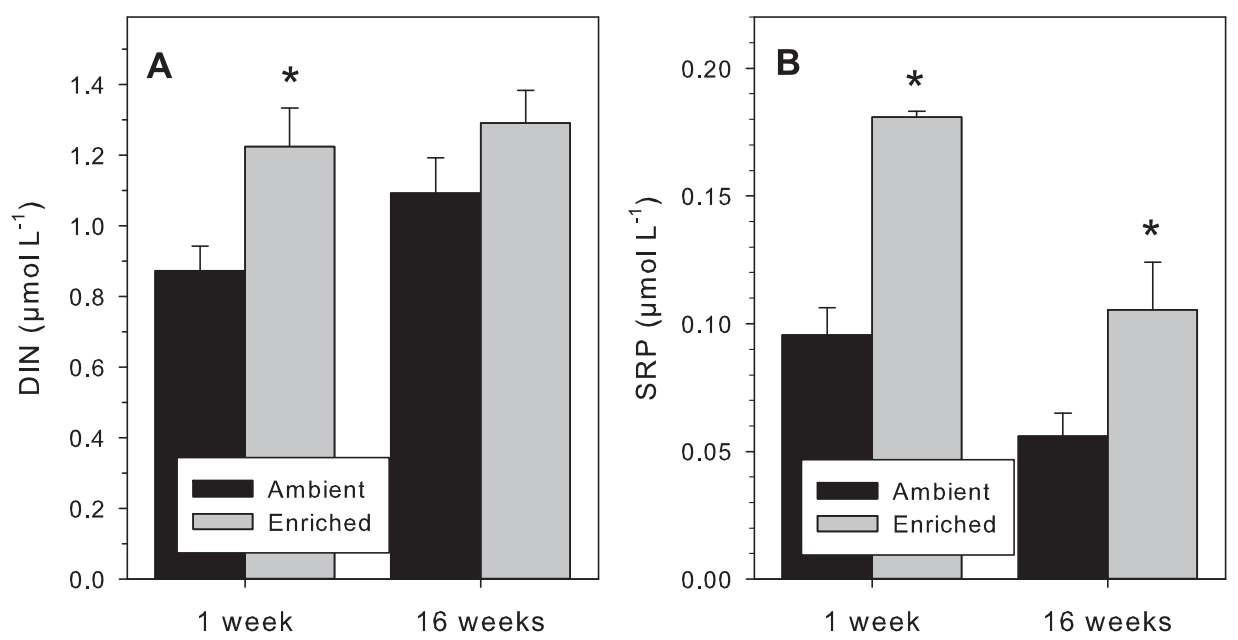

Figure 1. Inorganic nutrient concentrations. Shown are concentrations for ambient and enriched treatments of week 1 and week 16 directly above analyzed frames. Panel A depicts concentrations of dissolved inorganic nitrogen (DIN) and panel B the concentrations of soluble reactive phosphate (SRP). Asterisks indicate significance $(P<0.05)$ of single t-tests. doi:10.1371/journal.pone.0062091.g001

skeleton by air-blasting, collected in FSW, and homogenized using an Ultra-Turrax ( $\mathrm{T} 18$ basic, IKA, Staufen, Germany; $30 \mathrm{~s}$ at 3,500 rpm). Zooxanthellae abundance was counted using an Improved Neubauer hemocytometer (Hausser Scientific, Horsham, PA). Cell numbers were counted in 6 grid squares à $4 \mu \mathrm{m}^{3}$ with 6 counts per sample (average count: 29 cells per grid square). To determine isotopic signatures of coral tissue and zooxanthellae, a modified version of [47] was used. The homogenate of coral tissue and zooxanthellae was centrifuged for $5 \mathrm{~min}$ in a tabletop centrifuge at 1,500 rpm to separate coral tissue and zooxanthellae. Recorded data were normalized to zooxanthellae $\mathrm{cm}^{-2}$ with surface area (see method described above). Homogenized coral tissue was first filtered on a GF/F filter and washed with MilliQ water to remove remaining salt. Subsequently, the filters were dried for 2-4 d at $40^{\circ} \mathrm{C}$ until constant weight and $\delta^{15} \mathrm{~N}$ signatures were determined relative to atmospheric nitrogen in an isotope ratio mass spectrometer (Finnigan Corp., San Jose, CA). Isolated zooxanthellae were freeze-dried and directly measured with the mass spectrometer. For Symbiodinium-typing, DNA was extracted using the DNeasy Plant Mini Kit (Qiagen, Hilden, Germany) according to the manufacturer's instructions. The ITS2 rDNA region was amplified with the primer pair ITSintfor2 and ITS2CLAMP [48] using PCR conditions described in [49]. Amplified fragments were separated on $8 \%$ polyacrylamide gels, following [50], and using a CIPHER DGGE KIT (CBS Scientific Company, Del Mar, CA). Gels were run at $150 \mathrm{~V}$ for $15 \mathrm{~h}$ and stained for $20 \mathrm{~min}$ with 1x SYBR Green (Invitrogen, Carlsbad, CA) and visualized on a Dark Reader Transilluminator (Clare Chemical Research, Dolores, CO). Symbiodinium types were determined by DGGE fingerprint profiles and sequencing. For sequencing, prominent band(s) were excised from the DGGE gel and re-amplified as described in [51]. Re-amplified products were purified following manufacturer's instructions for Illustra ExoStar (GE Life Sciences, Piscataway, NJ). Samples were sent for bidirectional Sanger sequencing to the KAUST BioScience Core Laboratory (Thuwal, Saudi Arabia). Sequences were trimmed for quality in CodonCode Aligner (CodonCode Corporation, Centerville, MA). Forward and reverse sequences were assembled into contigs and aligned using ClustalW. Each contig was BLASTed against a local database of Symbiodinium ITS2 sequences. Coral respiration rates, chlorophyll $a$, zooxanthellae abundance, and $\delta^{15} \mathrm{~N}$ isotopic signatures of corals and zooxanthellae were analyzed with Sigmaplot 12 (Systat Software, Point Richmond, CA) by twoway ANOVA. To meet parametric assumptions, $\delta^{15} \mathrm{~N}$ coral data for colony-time factorial analysis were exponential transformed, and chlorophyll $a$ and respiration data for genotype-time factorial analysis were square transformed.

\section{Coral Bacterial Community}

DNA from flash frozen coral fragments and water filters was extracted using the Qiagen DNeasy Plant Mini Kit (Qiagen, Hilden, Germany) according to the manufacturer's instruction. Coral tissue was separated from skeleton using high-pressure air and extraction buffer, while filters were bead-beaten with extraction buffer for 1 minute. For water samples, DNA of all filters from week 1 and of all filters from week 16 were pooled resulting in two water samples that represent a comprehensive reef water microbial composition from week 1 and week 16. For PCR amplification of the 16S rRNA gene, we used the primers $784 \mathrm{~F}$ and $1061 \mathrm{R}$ that amplify E. coli position 781 to 1,060 [52]. The primer sequences were 5'CTATGCGCCTTGCGAGCGCGCTGAGtaAGGATTAGATACGCTGGTA3' (784F) and 5'GGTATCGGCTCGGTCGGGGGATGAG(N) $)_{8}$ ctCRRGACGAGCTGACGAC3' (1061R). Primers include 454 LibA library adapters (underlined), a barcode (shown as N) [53], and a two base pair linker sequence to avoid barcode influence on the amplification (lowercase). PCRs were run in $30 \mu \mathrm{L}$ triplicates per sample with Qiagen Multiplex PCR Kit (Qiagen, Hilden, Germany) and $30 \mathrm{ng} / \mu \mathrm{L}$ of input DNA using the following protocol: $15 \mathrm{~min}$ at $95^{\circ} \mathrm{C}$, followed by 27 cycles of $95^{\circ} \mathrm{C}$ for $40 \mathrm{~s}, 55^{\circ} \mathrm{C}$ for $40 \mathrm{~s}, 72^{\circ} \mathrm{C}$ for $40 \mathrm{~s}$, and a final extension cycle of $10 \mathrm{~min}$ at $72^{\circ} \mathrm{C}$. PCR products were run on an $1 \%$ agarose gel to visualize successful amplification. Sample triplicates were pooled and then purified using PALL multi-well filter plates (Pall Corporation, Port Washington, NY) and a Millipore multiscreen HTS vacuum manifold (Millipore Corporation, Billerica, MA). DNA concentrations were measured using a Qubit 2.0 (Invitrogen, Carlsbad, USA) and adjusted to $30 \mathrm{ng} / \mu \mathrm{L}$ before subsequent pooling. The pooled sample ran on a $1 \%$ agarose gel to remove excess primers. DNA was subsequently isolated from the gel using the Qiagen MinElute Gel Extraction Kit (Qiagen, Hilden, Germany) according to manufacturer's instructions. PCR products were sequenced 
using Titanium FLX chemistry on a quarter of a picotiter plate. Raw pyrosequencing reads were processed using the open source software mothur v.1.28.0 [54] for error correction, taxonomical classification using the greengenes database [55], and calculation of alpha-diversity and beta-diversity indices. More specifically, sequencing resulted in a total of 166,741 reads with a median length of $303 \mathrm{bp}$. The reads were split according to barcodes, error corrected, and quality trimmed using PyroNoise [56] as implemented in mothur, and subsequently aligned to the SILVA database alignment v102 [57]. We removed any sequences that did not cover positions 26,988 to 34,113 (variable regions 5 and 6 of the $16 \mathrm{~S}$ rRNA gene). To reduce sequencing noise, a preclustering step as implemented in mothur (maximal two base pairs difference) was performed [58]. Further reads were removed after a check for chimeric sequences using UCHIME as implemented in mothur [59] and/or their identification as chloroplast or mitochondrial contamination. The resulting dataset of 112,414 sequence reads was used for all analyses. The mothur "classify.seqs" function was used to classify all sequences against the 2011 Green Genes database [55] as provided on the mothur webpage. For classification a bootstrap cutoff of $60 \%$ was used. For the UniFrac [60] analysis, the sequences were subsampled to the lowest number of sequences in any group (3,283 sequences, week 1, sample $\mathrm{C}$, treatment CA). The Principal Coordinate (PCoA) and ANOSIM analysis were also performed in mothur, the plot was generated using the ggplot2 package [61] in $\mathrm{R}$ [62]. All sequences are available in the NCBI Sequence Read Archive (http://www.ncbi.nlm.nih.gov/sra) under accession number SRA062645. Mann-Whitney U test was conducted in Sigmaplot 12 (Systat Software, Point Richmond, CA). To determine distinct Operational Taxonomic Units (OTUs) that were significantly associated with $A$. hemprichii under treatments of overfishing, eutrophication, or both, we used the statistical package indicspecies [63]. We chose a conservative approach considering only OTUs that were highly significantly $(P<0.01)$ associated with one or several sample groups.

\section{Results}

\section{Environmental Parameters and Coral Physiology}

Nutrient enrichment led to significant increases in dissolved inorganic nitrogen (DIN) and in soluble reactive phosphate (SRP) (Figure 1). A parallel study showed intensive algae growth (specifically filamentous algae) in caged and combined treatments on terracotta tiles that were installed on PVC frames identical to the ones used in this study [64]. As opposed to the tiles, the corals that were analyzed in this study were all free of algal overgrowth (with the exception of the sample from week 16, colony A, CF that died) during the study time, and we did not find significant differences between treatments, time, or a combination thereof for any of the investigated physiological coral parameters (Table 1, Figure S3). However, we did find significant differences between the coral colonies independent of in-situ treatments and those represented biological variance (Table 1, Figure S3). More specifically, coral samples from colony B differed from $\mathrm{C}$ in regard to respiration rates, colony $\mathrm{A}$ and $\mathrm{B}$ differed significantly from colony $\mathrm{C}$ in the chlorophyll $a$ measurements and colony $\mathrm{B}$ differed from $\mathrm{C}$ in zooxanthellae abundance after week 16 (Figure S3). All coral specimens were associated with the same Symbiodinium clade over the duration of the experiment (clade C41), banding profile designation and sequence analyses were congruent (Figure S4). Hence, the differences observed cannot be attributed to differences of Symbiodinium type performance and origin of coral colony was more important than treatment effect.

\section{Microbial Community of Corals and Reef Water}

We sequenced a total of 166,741 reads, of which 112,414 were left after error correcting, chimera detection, and undesirable mitochondrial and chloroplast sequence removal. We retrieved the highest number of reads from the water sample from week 1 (21,155 sequence reads), and the lowest number of reads from coral colony C, week 1, cage treatment (3,283 sequence reads). One coral fragment was dead after 16 weeks and left out from the remainder of the analyses (colony A, cage \& fertilizer treatment). Good's estimator of coverage [65] showed that the majority of bacterial diversity was captured in the sequence data with values ranging from 0.90 to 0.98 (Table 2). The number of bacterial operational taxonomic units (OTUs) in corals varied from 104 (coral C, week 1, cage \& fertilizer treatment) to 908 (coral B, week 16, treatment FE) spanning almost an order of magnitude difference in diversity between samples. We found a significantly higher number of OTUs in all coral samples from week 16 in comparison to week 1, irrespective of treatment and despite a higher average number of reads in samples from week 1 (MWU, $P=0.011$, median number of OTUs week $1=120$, median number of OTUs week $16=432$, all specimens were subsampled to 3,283 reads). This observation is also supported when counting the number of distinct OTUs that we detected. We identified a total of 4,442 distinct OTUs of which 3,290 were found in corals and 1,432 in water. After week 1 we found 818 OTUs in all coral samples, after week 16 we identified 2,780 OTUs in all coral samples. Accordingly, bacterial diversity of corals increased over time. The Inverse Simpson Index for diversity varied from 2.14 (coral C, week 1, cage \& fertilizer treatment) to 16.41 (coral A, week 16, fertilizer treatment). Overall, bacterial diversity between corals was highly variable but lower than in the water column. However, Simpson Evenness estimates ranged from 0.01 to 0.04 indicating few dominant bacterial taxa.

We classified all sequences to the family level in order to look into the composition of the sample-specific microbial assemblages (Figure 2). Water samples were markedly different from coral samples, but similar to each other. Bacteria of the family Endozoicimonaceae in the order Oceanospirillales of the class Gammaproteobacteria dominated the coral microbial community. Depending on the coral sample, bacteria of the family Endozoicimonaceae made up between $27 \%$ and $95 \%$ of the microbial community of $A$. hemprichii, irrespective of time point or treatment. Most interestingly, only two OTUs made up $>99 \%$ of all Endozoicomonas bacteria (these OTUs could not be classified to the species level). In total, seven OTUs (Otu0001, Otu0002, Otu0003, Otu0011, Otu0029, Otu0055, Otu0085) were consistently found across all coral samples and on average accounted for $>72 \%$ of the total number of bacteria (Table S1). Of these seven OTUs, the first two were classified as Endozoicomonas sp. and made up $69 \%$ of all reads. The remaining five OTUs consisted of three Proteobacteria (families Rhodobacteraceae, Burkholderiaceae, Hyphomonadaceae) and two bacteria in the phylum Bacteroidetes (family Flavobacteriaceae) that made up 3\% of all reads. Hence, in contrast to the substantial microbial richness identified in $A$. hemprichii (Table 2), the majority of bacteria in the coral samples were covered by only few bacterial species.

To further analyze differences in bacterial community composition between colonies, treatments, and time points (beta diversity), we summarized unweighted UniFrac distances between samples with principal coordinate analysis (PCoA) [60] (Figure 3). This analysis clustered the microbial communities according to time (ANOSIM $P<0.001$ ), and also, but not significantly, according to coral colony and/or treatment (e.g. colony A, week 1). Interestingly, specimens from week 1 separated mainly along 
Table 1. Results from 2-factorial ANOVA of physiological coral parameters.

\begin{tabular}{|c|c|c|c|c|c|c|c|c|c|c|c|}
\hline & \multirow[b]{2}{*}{ df } & \multicolumn{2}{|c|}{ Coral respiration } & \multicolumn{2}{|c|}{ Chlorophyll a } & \multicolumn{2}{|c|}{ Zooxanthellae } & \multicolumn{2}{|c|}{$\delta^{15} \mathrm{~N}$ Coral } & \multicolumn{2}{|c|}{$\delta^{15} \mathrm{~N}$ Zooxanthellae } \\
\hline & & $F$ & $P$ & $F$ & $P$ & $F$ & $P$ & $F$ & $P$ & $F$ & $P$ \\
\hline \multicolumn{12}{|c|}{ Treatment vs. Time } \\
\hline $\operatorname{Tr}$ & 2 & 0.146 & 0.866 & 0.439 & 0.655 & 0.380 & 0.693 & 0.419 & 0.668 & 0.495 & 0.622 \\
\hline $\mathrm{Ti}$ & 1 & 0.198 & 0.666 & 2.635 & 0.133 & 4.328 & 0.062 & 3.468 & 0.089 & 2.335 & 0.155 \\
\hline $\mathrm{Tr} \times \mathrm{Ti}$ & 2 & 0.882 & 0.444 & 0.218 & 0.807 & 0.471 & 0.636 & 1.468 & 0.272 & 1.425 & 0.282 \\
\hline \multicolumn{12}{|c|}{ Colony vs. Time } \\
\hline C & 2 & 4.814 & $0.034^{*}$ & 11.617 & $0.002^{*}$ & 2.653 & 0.115 & 0.266 & 0.771 & 1.918 & 0.193 \\
\hline $\mathrm{Ti}$ & 1 & 0.005 & 0.947 & 6.563 & $0.026^{*}$ & 9.071 & $0.012^{*}$ & 3.393 & 0.093 & 3.931 & 0.073 \\
\hline $\mathrm{C} \times \mathrm{Ti}$ & 2 & 2.284 & 0.152 & 2.671 & 0.113 & 3.599 & 0.063 & 0.611 & 0.560 & 1.240 & 0.327 \\
\hline
\end{tabular}

Response variables are shown in the first row and the independent factors in the first column.

Abbreviations: $\mathrm{Tr}=$ Treatment, $\mathrm{Ti}=\mathrm{Time}, \mathrm{C}=$ Coral Colony. Significant results $(P<0.05)$ are indicated by asterisks.

doi:10.1371/journal.pone.0062091.t001

axis 2, whereas specimens from week 16 separated mainly along axis 1 , indicating that the factor(s) driving community composition were different for both time points.

\section{Bacterial Species Associated with Nutrient Enrichment and Herbivore Exclusion in Corals}

In addition to community level patterns, we analyzed the association of single OTUs to time points and experimental treatments. We identified ten OTUs that were significantly associated to one or more experimental treatments at a significance level of $P<0.01$ (Table 3). One OTU (genus Nautella, species unclassified) was significantly associated with the cage \& fertilizer treatment in week 1 , but was also present in the cage \& fertilizer treatment in week 16 and the cage treatment in week 1 . After week 16, we identified nine OTUs that were significantly associated with an experimental treatment or a combination thereof. Two OTUs were overrepresented upon cage and fertilizer treatments, but interestingly not in the combined cage \& fertilizer treatment. Note that samples from only two colonies were analyzed for the combined treatment in week 16. The two OTUs belonged to the phylum Proteobacteria in the families Desulfovibrionaceae (Desulfovibrio capillatus) and NB1-i (not further classified)

Table 2. Summary statistics of $45416 \mathrm{~S}$ rRNA gene sequencing $(C A=$ cage, $F E=$ fertilizer, $C F=$ cage \& fertilizer).

\begin{tabular}{|c|c|c|c|c|c|c|c|c|}
\hline Time & Coral Colony & yTreatment & \# of Sequences & $\begin{array}{l}\text { Sequence } \\
\text { Coverage }\end{array}$ & $\begin{array}{l}\text { Number of } \\
\text { OTUs }\end{array}$ & $\begin{array}{l}\text { Inverse } \\
\text { Simpson Index }\end{array}$ & Chao1 & $\begin{array}{l}\text { Simpson } \\
\text { Evenness }\end{array}$ \\
\hline \multirow[t]{10}{*}{ Week 1} & A & CA & 4882 & 0.98 & 184 & 2.51 & 398.24 & 0.01 \\
\hline & A & $\mathrm{FE}$ & 6175 & 0.98 & 157 & 2.30 & 417.00 & 0.01 \\
\hline & A & $\mathrm{CF}$ & 4368 & 0.98 & 177 & 2.50 & 373.20 & 0.01 \\
\hline & B & $C A$ & 7167 & 0.98 & 206 & 5.54 & 432.11 & 0.03 \\
\hline & B & $\mathrm{FE}$ & 3938 & 0.98 & 149 & 5.77 & 457.08 & 0.04 \\
\hline & B & $\mathrm{CF}$ & 6595 & 0.98 & 143 & 2.21 & 353.91 & 0.02 \\
\hline & $C$ & CA & 3283 & 0.96 & 175 & 2.19 & 774.44 & 0.01 \\
\hline & $C$ & $\mathrm{FE}$ & 5489 & 0.99 & 139 & 5.26 & 353.50 & 0.04 \\
\hline & $C$ & CF & 4423 & 0.98 & 104 & 2.14 & 286.57 & 0.02 \\
\hline & Water & - & 21155 & 0.97 & 919 & 25.01 & 2947.22 & 0.03 \\
\hline \multirow[t]{10}{*}{ Week 16} & A & CA & 5331 & 0.96 & 411 & 5.27 & 922.88 & 0.01 \\
\hline & A & $\mathrm{FE}$ & 4158 & 0.91 & 659 & 16.41 & 1304.32 & 0.02 \\
\hline & A & $\mathrm{CF}$ & - & - & - & - & - & - \\
\hline & B & $C A$ & 5339 & 0.90 & 888 & 8.06 & 1764.99 & 0.01 \\
\hline & B & $\mathrm{FE}$ & 7505 & 0.92 & 908 & 5.72 & 2360.50 & 0.01 \\
\hline & B & CF & 3595 & 0.86 & 761 & 8.22 & 1880.81 & 0.01 \\
\hline & $C$ & CA & 3592 & 0.92 & 364 & 2.78 & 1160.38 & 0.01 \\
\hline & $C$ & $\mathrm{FE}$ & 5086 & 0.96 & 336 & 3.00 & 786.19 & 0.01 \\
\hline & $C$ & CF & 3965 & 0.98 & 112 & 2.20 & 373.77 & 0.02 \\
\hline & Water & - & 6368 & 0.92 & 724 & 23.50 & 2929.85 & 0.03 \\
\hline
\end{tabular}

Sample Week 16, colony A, CF died and was left out of the analysis.

doi:10.1371/journal.pone.0062091.t002 


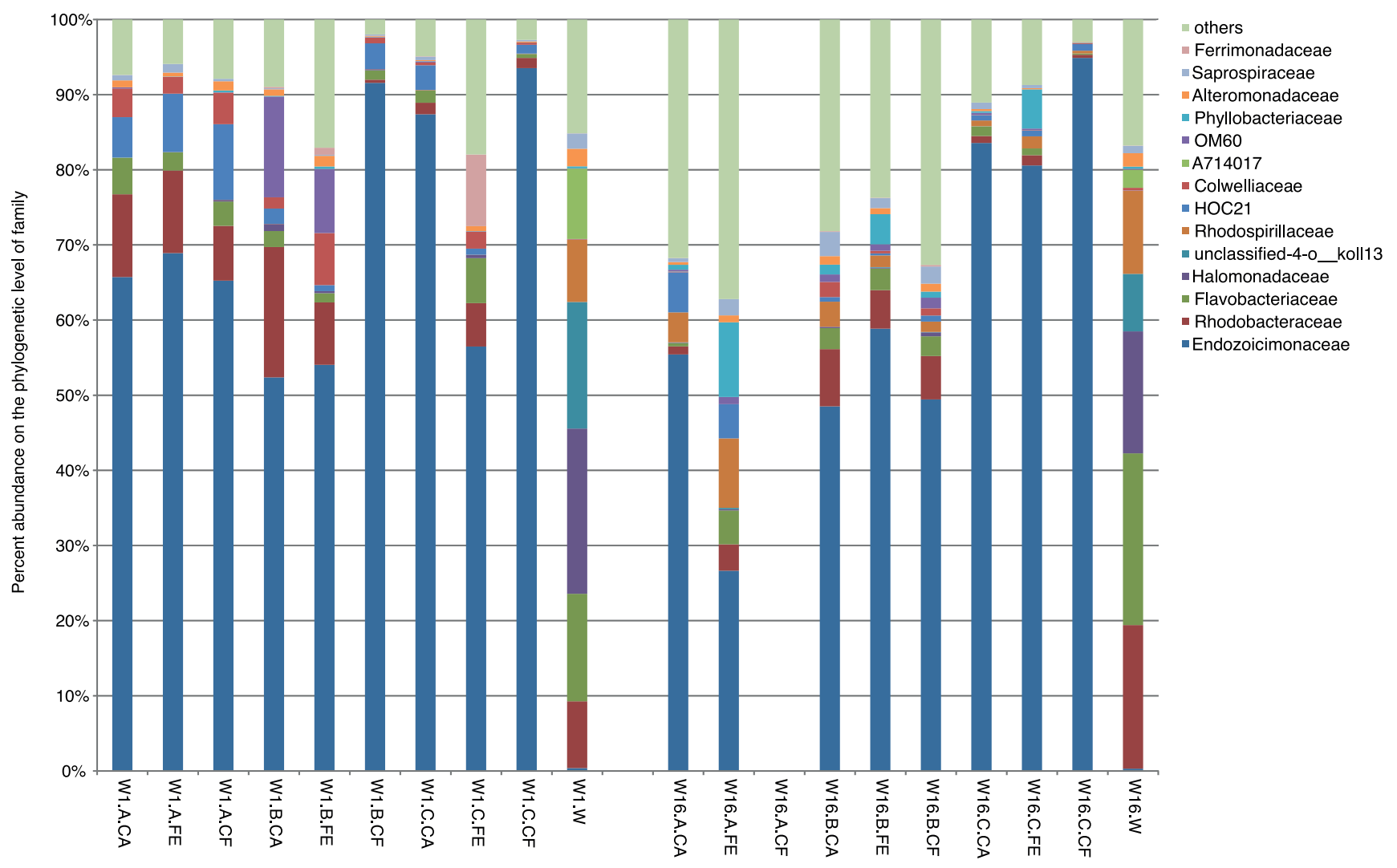

Figure 2. Bacterial taxonomy stack plot on the phylogenetic level of family. Each color represents each of the 15 most abundant families in all samples. All other taxa are grouped under category others. Bars are plotted according to 1$)$ time $(W 1=$ week 1, W16= week 16$)$, 2) coral mother colony $(A, B, C)$ or water (W), and 3) treatment (CA = cage, $F E=$ fertilizer, $C F=$ cage \& fertilizer). Sample W16.A.CF died and was left out of the analysis. doi:10.1371/journal.pone.0062091.g002

and were not identified in week 1 . Seven OTUs were significantly enriched upon fertilizer exposure. Of these OTUs, a bacterium from the genus Defluvibacter showed a very strong increase in abundance in comparison to all other treatments and time points. OTU counts ranged from 111 to 285 in all three coral specimens in week 16. In comparison, in all other treatments this OTU was either absent or present in low numbers (week 1, FE, 1 to 10 OTUs). The remaining six OTUs were exclusively identified after week 16 and belonged to the families Balneolaceae, Marinilabiaceae, and Saprospiraceae (phylum Bacteroidetes) and Phyllobacteriaceae, Rhodobacteraceae, Campylobacteraceae (phylum Proteobacteria).

\section{Discussion}

\section{Environmental Parameters}

With a complex experimental design that entails single and combined treatments, we were aiming at better separating the relative contribution of nutrient enrichment and overfishing to a combined manipulation. Interestingly, neither coral physiology data nor bacterial community data indicated that the combined treatment of cage \& fertilizer is a mere combination of the effects of each treatment on its own. Rather, each treatment produced a distinct and complex response that was not necessarily identified in the simultaneous and combined treatment. Furthermore, as a consequence of conducting a time course study during the summer months, all samples were subject to an increase and subsequent decrease in water temperature over the course of the project. While the average water temperature of week 1 was $28.7^{\circ} \mathrm{C}$ (min: $28.1^{\circ} \mathrm{C}$, max: $29.3^{\circ} \mathrm{C}$ ), the average water temperature after 10 weeks was $31.8^{\circ} \mathrm{C}(\min : 31.2$, $\max : 32.3)$, and the average water temperature in week 16 was $30.2^{\circ} \mathrm{C}\left(\min : 28.9^{\circ} \mathrm{C}\right.$, $\left.\max : 30.9^{\circ} \mathrm{C}\right)$. We see that the microbial community increases over time in all coral samples and this could be attributable to the variable temperature regime all samples were exposed to. Secondly, the coral fingers where subjected to the experimental conditions after being harvested from the respective mother colony without a time of acclimation. However, coral holobiont performance did not show a dependence on time, as physiological measures were similar after week 1 and week 16. Rather, physiology had a strong association with the coral colony the samples were taken from. Furthermore, all coral fingers were sampled at the same time, so that differences between treatments did still reflect biological variation as a response to experimental treatment.

\section{Coral Physiology}

A study by [66] found that turf algae reduce the effective photochemical efficiency of neighboring corals. Data from an experiment that was conducted in parallel showed that algal biomass had significantly increased over time as a result of reduced herbivory and in the combined treatment of reduced herbivory and increased nutrients, but not as a result of nutrient enrichment alone [64]. Here, we did not find significant differences between the treatments in coral holobiont performance as measured by respiration rates, chlorophyll $a$ levels, zooxanthellae abundance, or coral and algal isotopic nitrogen ratios. Hence, the consequences of overfishing and eutrophication on coral holobiont physiology in this study may have been too subtle to affect measured parameters. 


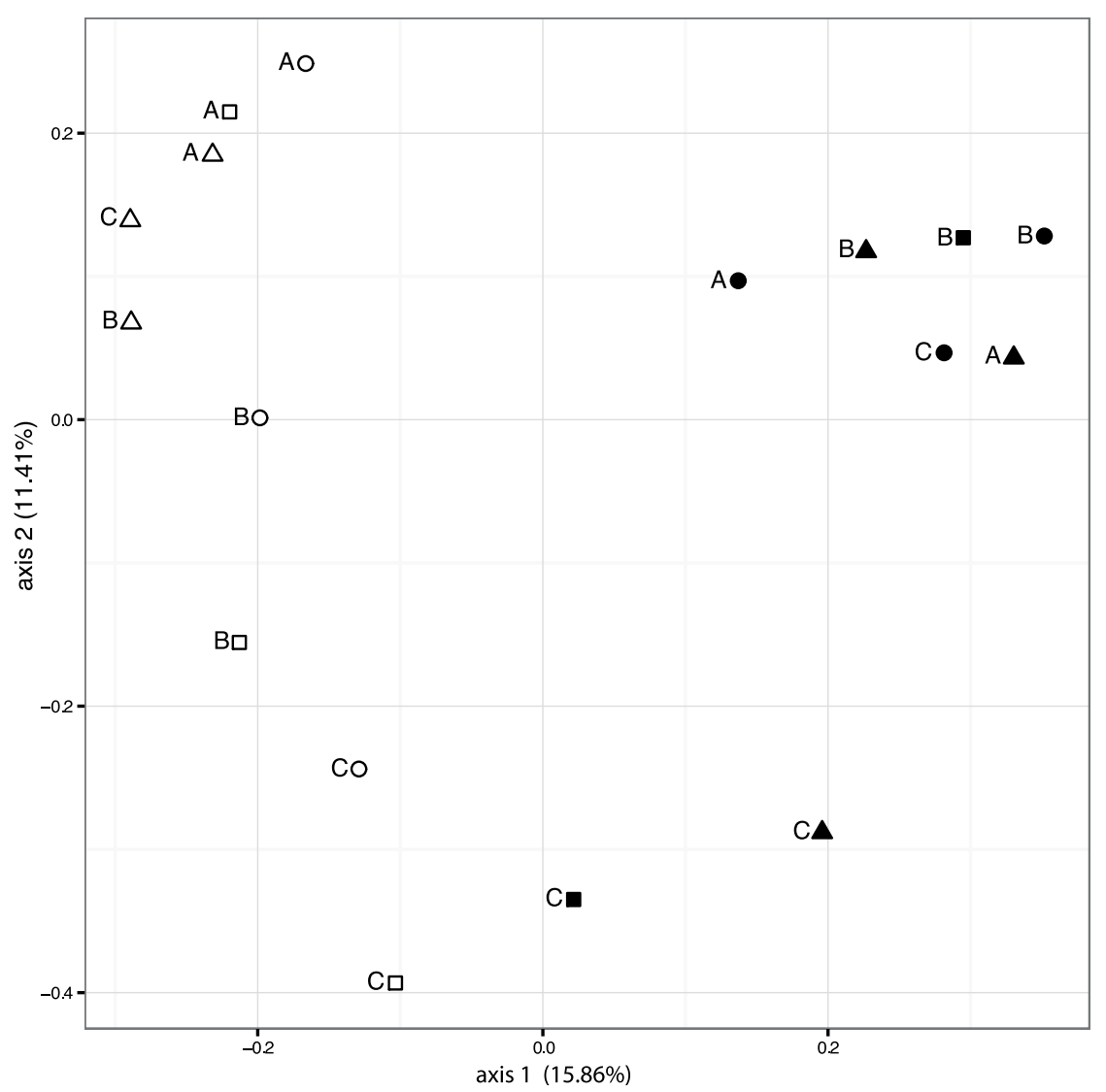

Figure 3. Principal Coordinate Analysis (PCoA) of unweighted UniFrac distances between coral samples. White symbols represent samples from week 1. Black symbols are samples from week 16. Coral colonies are depicted by the letter preceding the symbol (A, B, C). Circles denote cage, triangles denote fertilizer, and squares denote cage \& fertilizer treatments. Percentages given represent the amount of variance explained by the corresponding axis.

doi:10.1371/journal.pone.0062091.g003

At the same time, however, high nutrient loads do not necessarily have negative effects on holobiont performance (e.g. photosynthetic performance) as long as they are balanced [11]. In this study, we used a commercially available fertilizer that was composed of a balanced nutrient composition. In the water column, however, we found a stronger relative increase in SRP concentrations between ambient and enriched treatments than for DIN (Figure 1). Alternatively and/or additionally, the coral Acropora hemprichii may have proven more resilient to our experimental treatments than other coral species that have not been investigated here. Last, our experiment lasted for a total of 16 weeks. Overfishing and nutrient enrichment are often anthropogenically induced processes that can last much longer than the here chosen time frame, so that we may also have to consider a temporal component. Nonetheless, we were able to detect differences in the microbial community structure upon treatments and this underlines the importance of conducting field studies in a holobiont framework, taking both physiological and molecular measures into account.

\section{Microbial Community of Corals and Reef Water}

While we did not see significant differences in holobiont physiology as a result of either of the treatments, we could clearly pinpoint differences in the microbial community after treatments and in both time points. Most notably, the majority of bacteria $(>72 \%)$ did not change over time or treatment and were comprised of only seven OTUs. Accordingly, microbial changes were proportionally small and overall holobiont function (as indicated by the physiological data) may have been 'conserved'. Nonetheless, our data indicate that $A$. hemprichii harbors hundreds of different OTUs and our results are in accordance with previous estimates of coral microbial diversity [31,33]. In total, 4,442 distinct OTUs were detected in water and coral samples, 3,290 of which were associated with coral specimens. This number was highly variable though in regard to time point, treatment, and even coral colony. However, we saw a general increase in bacterial diversity after 16 weeks in comparison to week 1 . The latter indicates that the complexity of microbial assemblage is more a function of environment than mother colony. In contrast, bacterial diversity in water was stable over time. We conclude that the general increase of microbial complexity is specific to the coral and does not come from an increase in diversity over time in the surrounding water column. Several other studies [32,67] found a stable microbial community over time, however, coral-associated bacterial communities analyzed by [35] were not stable and grouped according to sampling time.

Endozoicomonas have now been identified in a number of studies and seem to be present in many marine invertebrates [33,68-74]. While we report on samples from a limited geographic range, we assume that Endozoicomonas is predominant in A. hemprichii across its range, given its strong presence irrespective of time or treatment in our study. Furthermore, it is interesting to note that only two OTUs made up $>99 \%$ of all Endozoicomonas bacteria. This indicates that the association of Endozoicomonas to A. hemprichii is 


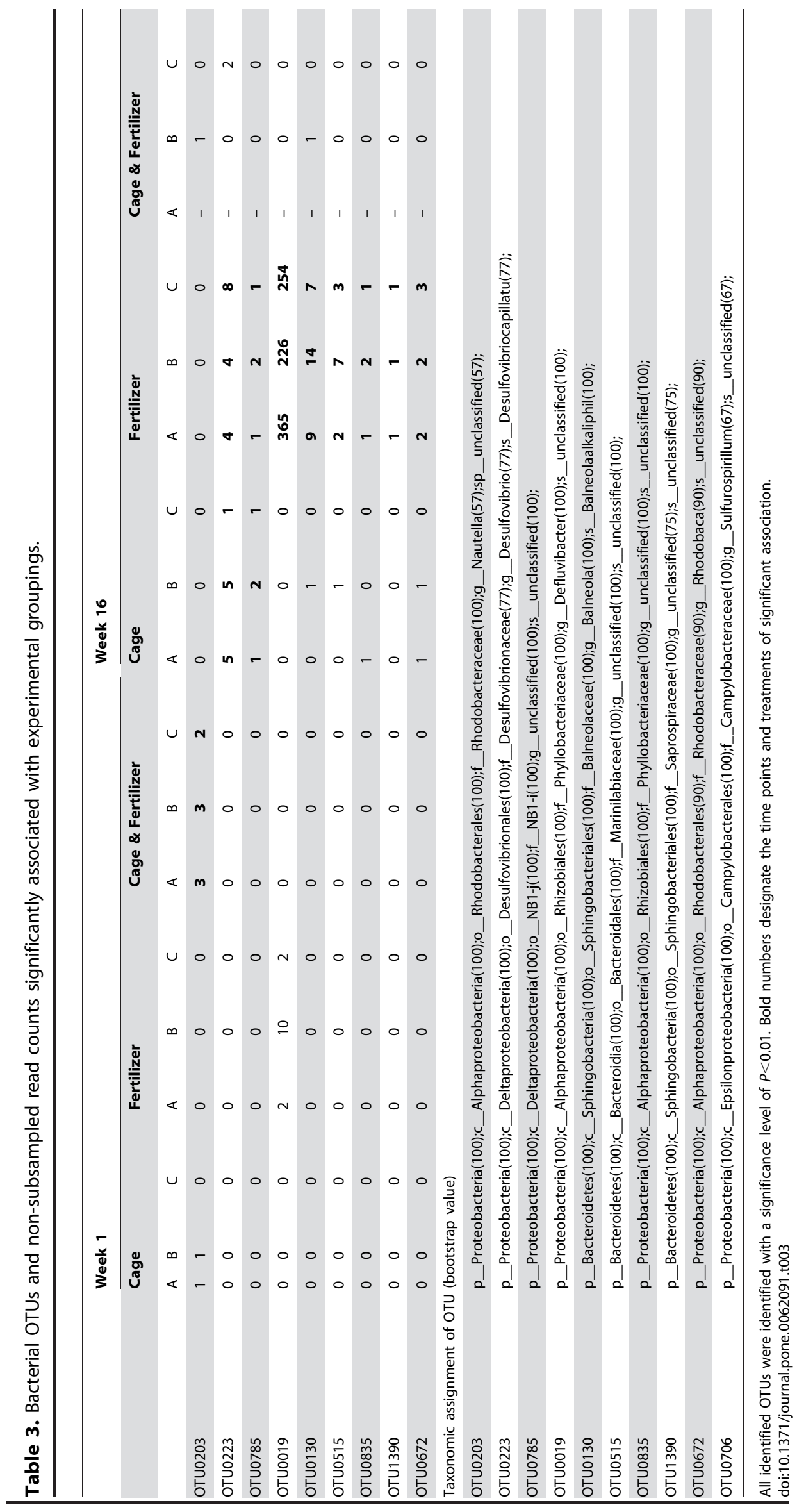


very specific. Different members of the Oceanospirillales order (to which Endozoicomonas belong) include obligatory heterotrophic rodlike bacteria known for biofilm production that allows other bacteria to colonize surfaces [73]. It is tempting to speculate on such a function for Endozoicomonas suggesting that they may play a key symbiotic role as an "architect microbe" that structure and contribute to microbial community function.

UniFrac distance significantly separated samples according to time. However, it seems that the factors driving sample separation were not the same between both time points as samples from week 1 show little differentiation on axis 1 but high differentiation on axis 2. In contrast, and to a lesser degree, samples from week 16 did separate along axis 1 and showed less variance on axis 2. In line with a longer treatment exposure we would expect a stronger separation by treatment after week 16 , but the phenotypic reaction may be complex and the clustering of samples from week 16 a result of origin, treatment effect, and time. The results from our microbial species analysis however do support a stronger treatment effect with time.

\section{Bacterial Species Associated with Nutrient Enrichment and Herbivore Exclusion in Corals}

In the analysis of bacterial OTUs specifically associated with treatments, we found more OTUs in single treatments after week 16 (nine OTUs vs. one OTU after week 1), and we also found a higher abundance of significantly associated OTUs after week 16. The finding that coral associated microbial communities respond to treatments supports previous findings that show that bacterial assemblages vary under different conditions such as increased temperature, elevated nutrients, dissolved organic carbon loading, and reduced $\mathrm{pH}$ [13]. Interestingly, the combined cage \& fertilizer treatment did not show the largest effect size. At the same time, however, the sample for microbial community analysis from colony A of the combined cage \& fertilizer treatment died in the process of the experiment. As a consequence, we had less statistical power to detect significant associations of OTUs to the treatment effect. Accordingly, the only significantly associated OTU we identified after week 1 was found in the combined cage \& fertilizer treatment. This OTU belongs to the genus Nautella representing marine bacteria belonging to the Roseobacter lineage of the Alphaproteobacteria. Up to date little is known about this type of bacteria but one member, Nautella sp. R11, has been shown to cause bleaching in the temperate-marine macroalga Delisea pulchra while switching from an opportunistic to a pathogenic lifestyle [75]. Overall, fertilizer treatment resulted in more associated OTUs than caging, and the two OTUs that were identified in caging after week 16 were also found in the fertilizer treatment after week 16 (Table 3). These two OTUs belonged to the phylum Proteobacteria, families Desulfovibrionaceae and NB1-i. While there is insufficient data available on bacterial species belonging to NB1-i, some members of the family Desulfovibrionaceae are sulfate-reducing [76]. We identified seven OTUs enriched in the fertilizer treatment after week 16 that were not enriched in any other treatment or time point. This notion points towards specific selection regimes under eutrophication, rather than a 'common' microbial community response as a result of general environmental disturbance. A bacterium from the genus Defluvibacter was highly abundant. Defluvibacter are aerobic denitrifiers, and members of this family are found in activated sludge from wastewater treatment plants [77,78]. It is also interesting to note that this bacterium is aerobic in contrast to the sulfate-reducing bacteria common in hypoxic environments that we identified after week 1 as a result of a combined treatment of nutrient-enrichment and caging. This indicates again that distinct bacterial species may gain a selection advantage and increase in abundance as a consequence of a specific treatment, rather than non-selective growth of opportunistic bacteria regardless of the underlying treatment. Of the other bacteria significantly abundant after 16 weeks in the fertilizer treatment, we identified members of Marinilabiaceae and Saprospiraceae. Bacteria of these families are found in nutrient rich environments such as whale fall or domestic and industrial wastewater treatment plants [79-81]. Last, we identified members of the Rhodobacteraceae that comprise a very diverse group with heterotrophic and phototrophic members [82], so that any functional implication is difficult. However, Rhodobacteraceae appear to do well under conditions of environmental change, i.e. many members seem to arise opportunistically [83-85]. Taken together, we were only able to derive species level annotations for two of the ten OTUs significantly enriched as a function of experimental treatment. Nevertheless, the functional associations we derived from the phylogenetic assignments correspond to the anticipated environmental consequences of a given treatment. For instance, we found bacteria from the family of Phyllobacteriaceae that contains denitrifying and nitrogen fixing bacterial species in the nutrient-enriched fertilizer treatment regime. Some bacteria within this family may probably be benefitting from the provided nitrogen (denitrifyers), others may be utilizing the iron and molybdenum of the fertilizer, both latter are critical metal cofactors for nitrogenase [86], the enzyme responsible for nitrogen fixation. Nitrogen fixation is an energetically costly process. Accordingly, we would not expect nitrogen fixing bacterial species to be enriched if other $\mathrm{N}$-sources such as provided by the fertilizer were available. Experimental work, however, demonstrates that $\mathrm{N}_{2}$ fixation still occurs at high ambient concentrations of nitrate [8791]. Furthermore, $\mathbf{N}_{2}$ fixation in eutrophic environments may be attributed to protecting the enzyme nitrogenase from inactivation [92,93].

\section{Conclusion}

This study analyzed the distinct and combined effects of nutrient enrichment and herbivore exclusion via in situ fertilizer diffusion, caging, and both over a period of 16 weeks on a coral reef in the Central Red Sea. While the physiology of the coral holobiont did not show significant differences in regard to $\mathrm{O}_{2}$ consumption, zooxanthellae counts and identity, chlorophyll $a$, or nitrogen isotopic ratios in the coral tissue as a function of experimental treatment, the bacterial communities derived from the different treatments illustrate that the microbial assemblage of the coral holobiont is variable and a consequence of mother colony, environmental conditions, and time. This underlines the importance of conducting field studies in a holobiont framework, taking both, physiological and molecular measures into account. Secondly, the functional associations of overrepresented bacteria in the treatments corresponded well with the environmental footprints of a given treatment (e.g. we found nitrogen fixing and denitrifying bacterial species in the nutrient-enriched fertilizer treatment regime). However, they were not stable over time indicating that the presence of potential indicator bacterial species may vary. Notably, the majority of bacterial cells of $A$. hemprichii were provided by a few OTUs of the genus Endozoicomonas that formed a stable association.

\section{Supporting Information}

Figure S1 Study site. Right panel shows position of the study area in the Red Sea. The circle on the left panel indicates study site at the Northern tip of Al Fahal-reef about $13 \mathrm{~km}$ off the SaudiArabian coast.

(EPS) 
Figure S2 Treatment scheme. Coral fingers were attached to stainless steel screws on PVC frames with cable ties. A: cage treatment imitating overfishing pressures, frame with coral fragments underneath. B: fertilizer treatment imitating eutrophication pressures with slow releasing fertilizer diffusing out of the red bars. C: combined treatment of cage \& fertilizer as in A and B. (EPS)

Figure S3 Physiological parameters of corals and zooxanthellae. The left column shows the comparisons of treatments, and the right column the comparisons of coral colonies. Given P-values are from a 2-factorial ANOVA. See Table 1 for full results. Abbreviations used: $\mathrm{Tr}=$ Treatment, $\mathrm{Ti}=$ Time, $\mathrm{G}=$ Genotype. Asterisks indicate significant differences between two groups. (EPS)

Figure S4 DGGE banding pattern of ITS2 from all coral samples. Please note that the coral samples are not depicted in a temporal order.

(PDF)

\section{References}

1. Hoegh-Guldberg O, Mumby PJ, Hooten AJ, Steneck RS, Greenfield P, et al. (2007) Coral reefs under rapid climate change and ocean acidification. Science 318: 1737-1742.

2. Hughes T, Baird A, Bellwood D, Card M, Connolly S, et al. (2003) Climate change, human impacts, and the resilience of coral reefs. Science 301: 929-933.

3. Hughes T, Rodrigues M, Bellwood D, Ceccarelli D, Hoegh-Guldberg O, et al. (2007) Phase shifts, herbivory, and the resilience of coral reefs to climate change. Current Biology 17: 360-365.

4. Pandolfi JM, Bradbury RH, Sala E, Hughes TP, Bjorndal KA, et al. (2003) Global trajectories of the long-term decline of coral reef ecosystems. Science 301: 955-958.

5. Wild C, Hoegh-Guldberg O, Naumann MS, Colombo-Pallotta MF, Ateweberhan M, et al. (2011) Climate change impedes scleractinian corals as primary reef ecosystem engineers. Marine and Freshwater Research 62: 205-215.

6. Mumby PJ, Harborne AR (2010) Marine reserves enhance the recovery of corals on Caribbean reefs. PLoS ONE 5: e8657.

7. Sweatman H (2008) No-take reserves protect coral reefs from predatory starfish. Current Biology 18: R598-R599.

8. Loya Y, Lubinevsky H, Rosenfeld M, Kramarsky-Winter E (2004) Nutrient enrichment caused by in situ fish farms at Eilat, Red Sea is detrimental to coral reproduction. Marine Pollution Bulletin 49: 344-353.

9. Ferrier-Pagès C, Gattuso JP, Dallot S, Jaubert J (2000) Effect of nutrient enrichment on growth and photosynthesis of the zooxanthellate coral Stylophora pistillata. Coral Reefs 19: 103-113.

10. Kinsey DW, Davies PJ (1979) Effects of elevated nitrogen and phosphorus on coral reef growth. Limnology and Oceanography 24: 935-940.

11. Wiedenmann J, D'Angelo C, Smith EG, Hunt AN, Legiret F-E, et al. (2013) Nutrient enrichment can increase the susceptibility of reef corals to bleaching. Nature Climate Change 3: 160-164.

12. Voss JD, Richardson LL (2006) Nutrient enrichment enhances black band disease progression in corals. Coral Reefs 25: 569-576.

13. Vega Thurber R, Willner-Hall D, Rodriguez-Mueller B, Desnues C, Edwards RA, et al. (2009) Metagenomic analysis of stressed coral holobionts. Environmental Microbiology 11: 2148-2163.

14. Lapointe B (1997) Nutrient thresholds for bottom-up control of macroalgal blooms on coral reefs in Jamaica and southeast Florida. Limnology and Oceanography 42: 1119-1131.

15. McClanahan TR, Cokos B, Sala E (2002) Algal growth and species composition under experimental control of herbivory, phosphorus and coral abundance in Glovers Reef, Belize. Marine Pollution Bulletin 44: 441-451.

16. McClanahan TR, Sala E, Mumby PJ, Jones S (2004) Phosphorus and nitrogen enrichment do not enhance brown frondose "macroalgae". Marine Pollution Bulletin 48: 196-199.

17. Miller MW, Hay ME (1996) Coral-seaweed-grazer-nutrient interactions on temperate reefs. Ecological Monographs 66: 323-344.

18. Birrell CL, McCook LJ, Willis BL, Diaz-Pulido GA (2008) Effects of benthic algae on the replenishment of corals and the implications for the resilience of coral reefs. Oceanography and Marine Biology an Annual Review 46: 25-64.

19. Schaffelke B, Mellors J, Duke NC (2005) Water quality in the Great Barrier Reef region: responses of mangrove, seagrass and macroalgal communities. Marine Pollution Bulletin 51: 279-296.

20. Paul VJ, Kuffner IB, Walters LJ, Ritson-Williams R, Beach KS, et al. (2011) Chemically-mediated interactions between macroalgae, Dictyota spp., and multiple life-history stages of the coral Porites astreoides. Marine Ecology Progress Series 426: 161-170.
Table S1 Overview over sequence counts, taxonomic classification, and $16 \mathrm{~S}$ reference amplicon sequence for all OTUs identified.

(XLSX)

\section{Acknowledgments}

We are grateful for field support to the CMOR team at KAUST, L. Smith, F. Mallon, E. Aravantinos and the boat crew K. Al-Moullad, E. Al-Jahdali, G. Al-Jahdali. We also thank the Bioscience Core Lab at KAUST, A. Robertson and M.S. Alarawi for sequencing, and C. Arif for DGGE-ITS2typing of Symbiodinium clades of the coral samples.

\section{Author Contributions}

Conceived and designed the experiments: CJ CR CW CRV. Performed the experiments: JFVL MA GJ CR. Analyzed the data: GRV JFVL GJ TB MA CR. Contributed reagents/materials/analysis tools: CW CRV. Wrote the paper: GJ CRV.

21. Rasher DB, Hay ME (2010) Chemically rich seaweeds poison corals when not controlled by herbivores. Proceedings of the National Academy of Sciences of the United States of America 107: 9683-9688.

22. Rasher DB, Stout EP, Engel S, Kubanek J, Hay ME (2011) Macroalgal terpenes function as allelopathic agents against reef corals. Proceedings of the National Academy of Sciences of the United States of America 108: 17726-17731.

23. Haas AF, Nelson CE, Kelly LW, Carlson CA, Rohwer F, et al. (2011) Effects of coral reef benthic primary producers on dissolved organic carbon and microbial activity. PLoS ONE 6: e27973.

24. Smith JE, Shaw M, Edwards RA, Obura D, Pantos O, et al. (2006) Indirect effects of algae on coral: algae-mediated, microbe-induced coral mortality. Ecology Letters 9: 835-845.

25. Wild C, Haas A, Naumann M, Mayr G, El-Zibdah M (2009) Comparative investigation of organic matter release by corals and benthic reef algae implications for pelagic and benthic microbial metabolism. Proceedings of the 11th International Coral Reef Symposium: 1319-1323.

26. Vega Thurber R, Burkepile DE, Correa AMS, Thurber AR, Shantz AA, et al. (2012) Macroalgae decrease growth and alter microbial community structure of the reef-building coral, Porites astreoides. PLoS ONE 7: e44246.

27. Kline DI, Kuntz NM, Breitbart M, Knowlton N, Rohwer F (2006) Role of elevated organic carbon levels and microbial activity in coral mortality. Marine Ecology Progress Series 314: 119-125.

28. Barott KL, Rohwer FL (2012) Unseen players shape benthic competition on coral reefs. Trends in Microbiology 20: 621-628.

29. Rosenberg E, Koren O, Reshef L, Efrony R, Zilber-Rosenberg I (2007) The role of microorganisms in coral health, disease and evolution. Nature Reviews Microbiology 5: 355-362.

30. Knowlton N, Rohwer F (2003) Multispecies microbial mutualisms on coral reefs: the host as a habitat. American Naturalist 162: S51-S62.

31. Mouchka ME, Hewson I, Harvell CD (2010) Coral-associated bacterial assemblages: current knowledge and the potential for climate-driven impacts. Integrative and Comparative Biology 50: 662-674.

32. Rohwer F, Seguritan V, Azam F, Knowlton N (2002) Diversity and distribution of coral-associated bacteria. Marine Ecology Progress Series 243: 1-10.

33. Sunagawa S, Woodley CM, Medina M (2010) Threatened corals provide underexplored microbial habitats. PLoS ONE 5: e9554.

34. Bourne DG, Munn CB (2005) Diversity of bacteria associated with the coral Pocillopora damicornis from the Great Barrier Reef. Environmental Microbiology 7: 1162-1174.

35. Ceh J, Van Keulen M, Bourne DG (2010) Coral-associated bacterial communities on Ningaloo Reef, Western Australia. FEMS Microbiology Ecology 75: 134-144.

36. Apprill A, Marlow HQ, Martindale MQ, Rappé MS (2009) The onset of microbial associations in the coral Pocillopora meandrina. The ISME Journal 3: 685-699.

37. Burke C, Steinberg P, Rusch D, Kjelleberg S, Thomas T (2011) Bacterial community assembly based on functional genes rather than species. Proceedings of the National Academy of Sciences of the United States of America 108: $14288-14293$

38. Rohwer F, Breitbart M, Jara J, Azam F, Knowlton N (2001) Diversity of bacteria associated with the Caribbean coral Montastraea franksi. Coral Reefs 20: 85-91.

39. Pantos O, Cooney RP, Le Tissier MDA, Barer MR, O'Donnell AG, et al. (2003) The bacterial ecology of a plague-like disease affecting the Caribbean coral Montastrea annularis. Environmental Microbiology 5: 370-382. 
40. Wegley L, Edwards R, Rodriguez-Brito B, Liu H, Rohwer F (2007) Metagenomic analysis of the microbial community associated with the coral Porites astreoides. Environmental Microbiology 9: 2707-2719.

41. Wilkinson G (2008) Status of coral reefs of the world: 2008. Townsville: Australian Institute of Marine Science.

42. Burke LM, Reytar K, Spalding M, Perry A (2011) Reefs at risk revisited. Washington, DC: World Resources Institute.

43. Veron JEN (2000) Corals of the world. Townsville, Australia: Australian Institute of Marine Science (AIMS).

44. Grasshoff K, Kremling K, Ehrhardt M (1999) Methods of seawater analysis. Weinheim: Wiley-VCH.

45. Aminot A, Kérouel R, Birot D (2001) A flow injection-fluorometric method for the determination of ammonium in fresh and saline waters with a view to in situ analyses. Water Res 35: 1777-1785.

46. Naumann MS, Niggl W, Laforsch C, Glaser C, Wild C (2009) Coral surface area quantification-evaluation of established techniques by comparison with computer tomography. Coral Reefs 28: 109-117.

47. Muscatine L, Kaplan I (1994) Resource partitioning by reef corals as determined from stable isotope composition - II. $\delta 15 \mathrm{~N}$ of zooxanthellae and animal tissue vs depth. Pacific Science 48: 304-312.

48. LaJeunesse TC, Trench R (2000) Biogeography of two species of Symbiodinium (Freudenthal) inhabiting the intertidal sea anemone Anthopleura elegantissima (Brandt). Biological Bulletin 199: 126-134.

49. LaJeunesse TC, Loh WKW, Van Woesik R, Hoegh-Guldberg O, Schmidt GW, et al. (2003) Low symbiont diversity in southern Great Barrier Reef corals, relative to those of the Caribbean. Limnology and Oceanography 48: 20462054 .

50. Sampayo E, Dove S, LaJeunesse TC (2009) Cohesive molecular genetic data delineate species diversity in the dinoflagellate genus Symbiodinium. Molecular Ecology 18: 500-519.

51. LaJeunesse TC (2002) Diversity and community structure of symbiotic dinoflagellates from Caribbean coral reefs. Marine Biology 141: 387-400.

52. Andersson AF, Lindberg M, Jakobsson H, Bäckhed F, Nyrén P, et al. (2008) Comparative analysis of human gut microbiota by barcoded pyrosequencing. PLoS ONE 3: e2836.

53. Hamady M, Walker JJ, Harris JK, Gold NJ, Knight R (2008) Error-correcting barcoded primers for pyrosequencing hundreds of samples in multiplex. Nature Methods 5: 235-237.

54. Schloss PD, Westcott SL, Ryabin T, Hall JR, Hartmann M, et al. (2009) Introducing mothur: open-source, platform-independent, community-supported software for describing and comparing microbial communities. Applied and Environmental Microbiology 75: 7537-7541

55. McDonald D, Price MN, Goodrich J, Nawrocki EP, DeSantis TZ, et al. (2012) An improved Greengenes taxonomy with explicit ranks for ecological and evolutionary analyses of bacteria and archaea. The ISME Journal 6: 610-618.

56. Quince C, Lanzen A, Davenport RJ, Turnbaugh PJ (2011) Removing noise from pyrosequenced amplicons. BMC Bioinformatics 12: 38.

57. Pruesse E, Quast C, Knittel K, Fuchs BM, Ludwig W, et al. (2007) SILVA: a comprehensive online resource for quality checked and aligned ribosomal RNA sequence data compatible with ARB. Nucleic Acids Research 35: 7188-7196.

58. Huse SM, Welch DM, Morrison HG, Sogin ML (2010) Ironing out the wrinkles in the rare biosphere through improved OTU clustering. Environmental Microbiology 12: 1889-1898.

59. Edgar RC, Haas BJ, Clemente JC, Quince C, Knight R (2011) UCHIME improves sensitivity and speed of chimera detection. Bioinformatics 27: 2194 2200 .

60. Lozupone G, Knight R (2005) UniFrac: a new phylogenetic method for comparing microbial communities. Applied and Environmental Microbiology 71: $8228-8235$.

61. Wickham H (2009) ggplot2: Elegant Graphics for Data Analysis. New York: Springer.

62. RDC Team (R Development Core Team) (2012) R: A language and environment for statistical computing (Vienna: R Foundation for Statistical Computing). http://www.r-project.org/.

63. De Cáceres M, Legendre P (2009) Associations between species and groups of sites: indices and statistical inference. Ecology 90: 3566-3574.

64. Jessen C, Roder C, Villa Lizcano J, Voolstra CR, Wild C (2012) Top-down and bottom-up effects on Red Sea coral reef algae. Proceedings of the 12th International Coral Reef Symposium.

65. Good IJ (1953) The population frequencies of species and the estimation of population parameters. Biometrika 40: 237-264.

66. Vermeij MJA, van Moorselaar I, Engelhard S, Hörnlein C, Vonk SM, et al. (2010) The effects of nutrient enrichment and herbivore abundance on the ability of turf algae to overgrow coral in the Caribbean. PLoS ONE 5: e14312.

67. Littman RA, Willis BL, Pfeffer C, Bourne DG (2009) Diversities of coralassociated bacteria differ with location, but not species, for three acroporid corals on the Great Barrier Reef. FEMS Microbiology Ecology 68: 152-163.
68. Zielinski FU, Pernthaler A, Duperron S, Raggi L, Giere O, et al. (2009) Widespread occurrence of an intranuclear bacterial parasite in vent and seep bathymodiolin mussels. Environmental Microbiology 11: 1150-1167.

69. Bourne D, Iida Y, Uthicke S, Smith-Keune C (2007) Changes in coralassociated microbial communities during a bleaching event. The ISME Journal 2: $350-363$.

70. Kurahashi M, Yokota A (2007) Endozoicomonas elysicola gen. nov., sp nov., a gamma-proteobacterium isolated from the sea slug Elysia ornata. Systematic and Applied Microbiology 30: 202-206.

71. Bayer T, Arif C, Ferrier-Pagès C, Zoccola D, Aranda M, et al. (2013) Bacteria of the genus Endozoicomonas dominate the microbiome of the Mediterranean gorgonian coral Eunicella cavolini. Marine Ecology Progress Series.

72. Jensen S, Duperron S, Birkeland NK, Hovland M (2010) Intracellular Oceanospirillales bacteria inhabit gills of Acesta bivalves. FEMS Microbiology Ecology 74: 523-533.

73. Speck MD, Donachie SP (2012) Widespread Oceanospirillaceae Bacteria in Porites spp. Journal of Marine Biology 2012.

74. Thiel V, Leininger S, Schmaljohann R, Brümmer F, Imhoff JF (2007) Spongespecific bacterial associations of the Mediterranean sponge Chondrilla nucula (Demospongiae, Tetractinomorpha). Microbial Ecology 54: 101-111.

75. Fernandes N, Case RJ, Longford SR, Seyedsayamdost MR, Steinberg PD, et al. (2011) Genomes and virulence factors of novel bacterial pathogens causing bleaching disease in the marine red alga Delisea pulchra. PLoS ONE 6: e27387.

76. Devereux R, He S, Doyle C, Orkland S, Stahl D, et al. (1990) Diversity and origin of Desulfovibrio species: phylogenetic definition of a family. Journal of Bacteriology 172: 3609-3619.

77. Fritsche K, Auling G, Andreesen JR, Lechner U (1999) Defluvibacter lusatiae gen. nov., sp. nov., a new chlorophenol-degrading member of the $\alpha$-2 subgroup of Proteobacteria. Systematic and Applied Microbiology 22: 197-204.

78. Xiao J, Jiang H, Chu S (2012) Isolation and identification of aerobic denitrifying bacterium Defluvibacter lusatiensis strain DN7 and its heterotrophic nitrification ability. Chinese Journal of Applied Ecology 23: 1979-1984.

79. Goffredi SK, Orphan VJ (2009) Bacterial community shifts in taxa and diversity in response to localized organic loading in the deep sea. Environmental Microbiology 12: 344-363.

80. Kong Y, Xia Y, Nielsen JL, Nielsen PH (2007) Structure and function of the microbial community in a full-scale enhanced biological phosphorus removal plant. Microbiology 153: 4061-4073.

81. Xia Y, Kong Y, Thomsen TR, Nielsen PH (2008) Identification and ecophysiological characterization of epiphytic protein-hydrolyzing Saprospiraceae ("Candidatus Epiflobacter" spp.) in activated sludge. Applied and Environmental Microbiology 74: 2229-2238.

82. Garrity GM, Bell JA, Lilburn TG (2004) Taxonomic outline of the prokaryotes. Bergey's Manual of Systematic Bacteriology. New York: Springer.

83. Chen CP, Tseng CH, Chen CA, Tang SL (2010) The dynamics of microbial partnerships in the coral Isopora palifera. The ISME Journal 5: 728-740.

84. Christie-Oleza JA, Fernandez B, Nogales B, Bosch R, Armengaud J (2011) Proteomic insights into the lifestyle of an environmentally relevant marine bacterium. The ISME Journal 6: 124-135.

85. Meron D, Atias E, Kruh LI, Elifantz H, Minz D, et al. (2010) The impact of reduced $\mathrm{pH}$ on the microbial community of the coral Acropora eurystoma. The ISME Journal 5: 51-60.

86. Howard J, Rees D (1996) Structural Basis of Biological Nitrogen-Fixation. Chemical Reviews 96: 2965-2982.

87. Holl CM, Montoya JP (2005) Interactions between nitrate uptake and nitrogen fixation in continuous cultures of the marine diazotroph Trichodesmium (Cyanobacteria). Journal of Phycology 41: 1178-1183.

88. Moisander PH, Beinart RA, Hewson I, White AE, Johnson KS, et al. (2010) Unicellular cyanobacterial distributions broaden the oceanic N2 fixation domain. Science 327: 1512-1514.

89. Mulholland MR, Ohki K, Capone DG (2001) Nutrient controls on nitrogen uptake and metabolism by natural populations and cultures of Trichodesmium (Cyanobacteria). Journal of Phycology 37: 1001-1009.

90. Sohm JA, Hilton JA, Noble AE, Zehr JP, Saito MA, et al. (2011) Nitrogen fixation in the South Atlantic Gyre and the Benguela Upwelling System. Geophysical Research Letters 38: L16608.

91. Voss M, Croot P, Lochte K, Mills M, Peeken I (2004) Patterns of nitrogen fixation along $10^{\circ} \mathrm{N}$ in the tropical Atlantic. Geophysical Research Letters 31: L23S09.

92. Rao AMF, Charette MA (2011) Benthic Nitrogen Fixation in an Eutrophic Estuary Affected by Groundwater Discharge. Journal of Coastal Research 28: 477-485.

93. Oneil JM, Capone DG (1989) Nitrogenase Activity in Tropical Carbonate Marine-Sediments. Marine Ecology Progress Series 56(1-2): 145-156. 